\title{
Hydrotalcites supported on carbon nanofibers as solid base catalysts for the synthesis of MIBK
}

\author{
Ferry Winter, Vincent Koot, A. Jos van Dillen, John W. Geus, Krijn P. de Jong * \\ Department of Inorganic Chemistry and Catalysis, Debye Institute, Utrecht University, PO Box 80 083, 3508 TB Utrecht, The Netherlands
}

Received 8 July 2005; revised 5 September 2005; accepted 19 September 2005

Available online 18 October 2005

\begin{abstract}
Mechanically strong carbon nanofiber spheres of millimeter size were grown from methane over a preshaped $\mathrm{Ni} / \mathrm{SiO} 2$ catalyst. $\mathrm{Mg}-\mathrm{Al}$ hydrotalcites (HTs) were precipitated in the porous carbon bodies by consecutive impregnation of the reactants and an aging step. In a single sequence, HT loadings as high as $16 \mathrm{wt} \%$ were obtained. HTs turned out to be present as platelets with a lateral size of $\sim 20 \mathrm{~nm}$ supported on the carbon nanofibers. After activation by heat treatment and subsequent rehydration, a high number of accessible Brønsted base sites were found (0.70.9 mmol $\mathrm{g}_{\mathrm{HT}}^{-1}$ ), as determined by $\mathrm{CO}_{2}$ adsorption measurements. High specific activity of the supported HTs was found in the self-condensation of acetone, more than four times higher than that of unsupported catalysts. The greatly improved efficiency of the supported HTs was ascribed to the high number of active edge sites. Results show no loss of HTs from the carbon bodies after catalysis and demonstrate that the used catalyst can be easily reactivated by the thermal activation procedure. An efficient and mechanically strong catalyst for the single-stage liquid-phase synthesis of methyl isobutyl ketone from acetone and $\mathrm{H}_{2}$ at $331 \mathrm{~K}$ was obtained with the deposition of Pd and HTs on the same support.
\end{abstract}

(C) 2005 Elsevier Inc. All rights reserved.

Keywords: Hydrotalcite; Layered double hydroxide; Carbon nanofibers; Aldol condensation; Supported hydrotalcite; Solid base catalyst; Small hydrotalcite platelets; MIBK

\section{Introduction}

Interest has been growing in the use of hydrotalcites (HTs) as solid base catalysts for Knoevenagel condensations, Michael additions, and Claisen-Schmidt and aldol condensations [1-5], and also as support materials for noble metals [6-9]. For example, activated $\mathrm{Mg}-\mathrm{Al} \mathrm{HT}$ is capable of catalyzing liquid-phase condensation reactions at low temperatures with high activity and selectivity [4,10-16].

HT belongs to a class of anionic clay minerals also known as layered double hydroxides. Its structure closely resembles that of brucite, $\mathrm{Mg}(\mathrm{OH})_{2}$. In the latter structure, magnesium cations are six-coordinated by hydroxyl ions in edge-shared octahedra that form stacked layers. In HT, part of the $\mathrm{Mg}^{2+}$ ions are replaced by $\mathrm{Al}^{3+}$ ions, resulting in positively charged cation layers, with the charge balanced by anions situated together

\footnotetext{
* Corresponding author. Fax: +31 302511027.

E-mail address: k.p.dejong@ @chem.uu.nl (K.P. de Jong).
}

with water molecules in the interlayer $[1,17,18]$. The lateral size of the layers and the degree of stacking can be varied by changing the synthesis conditions [19].

By heat treating an HT [e.g., $\mathrm{Mg}_{4} \mathrm{Al}_{2}(\mathrm{OH})_{12} \mathrm{CO}_{3} \cdot 4 \mathrm{H}_{2} \mathrm{O}$ ] up to $723-773 \mathrm{~K}$, the layered structure is destroyed by decarboxylation and dehydroxylation of the cation layer, and a mixed oxide is formed. This mixed oxide exhibits Lewis basicity and can be used as a catalyst in various gas-phase reactions [20,21]. To obtain a highly active base catalyst for liquid-phase condensation reactions, the calcined HT must be rehydrated, which results in the reconstruction of the layered structure in which $\mathrm{CO}_{3}{ }^{2-}$ ions are replaced by $\mathrm{OH}^{-}$ions $[4,11-15,22,23]$. Recent studies showed that the actual active sites participating in catalysis are situated at the edges of the platelets [13,14,2426]. Efforts have been made to increase the number of edge sites of the HT platelets [13,24,25]; however, the exposed edge area is limited by the lateral size of the crystallites. The size in the lateral dimension can be varied by applying different crystallization temperatures, but the lower limit that was obtained up to recently is $60-70 \mathrm{~nm}[13,19,24,25]$. Further investiga- 
tion to synthesize smaller HT crystallites is therefore beneficial to obtain more efficient catalysts. Recently, we reported on supported HT platelets with a lateral size of $20 \mathrm{~nm}$, and the resulting activated catalyst showed very high activity in the selfcondensation of acetone and in the condensation of citral with acetone [27]. The significant increase in efficiency was found to be related to the small crystallite size of the HT platelets, which implies a high number of active sites.

Single-stage production of methyl isobutyl ketone (MIBK) has been investigated by a number of groups $[9,21,28,29]$. Currently, we are developing a catalyst system comprising a combination of activated HT as solid base catalyst for condensation and dehydration and Pd supported on carbon nanofibers for hydrogenation [23]. However, to use HT as a catalyst in such a slurry-phase process, it is advantageous to have mechanically strong catalyst particles available in the $20-100 \mu \mathrm{m}$ range, to facilitate fast removal of the catalyst by filtration. Ogawa and Kaiho [30] synthesized HT particles via homogeneous precipitation and were able to synthesize platelets of $20 \mu \mathrm{m}$. However, as discussed above, it is not preferable to obtain large platelets, because this implies a low number of active sites. Moreover, the mechanical strength of HT itself is rather low, and shaping these materials to strong catalyst particles is cumbersome. Furthermore, it is important to avoid the application of the commonly used type of binders, because these compounds could introduce as such catalytic sites that negatively affect the selectivity and decrease the accessibility of the basic sites of HT. Taking these aspects into account, we concluded that a different approach is needed.

Carbon nanofibers (CNFs) are mechanically strong and can be produced as bodies of interwoven fibers (skeins) with a high mesopore and macropore volume and no micropores [31,32]. Moreover, the shape and size of CNF bodies $(\mu \mathrm{m}-\mathrm{mm})$ can be controlled to a large extent, because the shape of the catalyst from which CNF is grown and the growth conditions determine the size, density, and shape of the ultimate CNF particles [33,34]. Earlier, Teunissen et al. [34] synthesized very strong CNF spheres of 3-5 mm out of methane at $843 \mathrm{~K}$ over a spherically shaped $20 \mathrm{wt} \% \mathrm{Ni}$ on $\mathrm{Al}_{2} \mathrm{O}_{3}$ catalyst. The increase in diameter of the spherical CNF particles was 3-fold that of the original $\mathrm{Ni} / \mathrm{Al}_{2} \mathrm{O}_{3}$ catalyst bodies. A disadvantage was the presence of alumina, which could not be fully removed by washing with acid or base [35]. The use of a suitable Ni on silica catalyst would be beneficial, because $\mathrm{SiO}_{2}$ is easily removed in a solution of $\mathrm{NaOH}$. Subsequent treatment of $\mathrm{CNF}$ in nitric acid removes exposed $\mathrm{Ni}$ and introduces oxygen-containing surface sites [36,37].

In this paper we report on an extensive study on the inclusion of $\mathrm{Mg} / \mathrm{Al} \mathrm{HT}$ and Pd in the pores of mechanically strong CNF bodies for the single-stage synthesis of MIBK, starting from our earlier research [27]. Because direct preparation of the active solid base catalyst is hardly possible, the precursor of the actual catalyst is $\mathrm{HT}$ with intercalated $\mathrm{CO}_{3}{ }^{2-}$ supported on $\mathrm{CNF}$. After heat treatment and rehydration of these materials, their performance as solid base catalysts was investigated in the condensation of acetone and compared with that of an unsupported HT, to derive the relationship between structure and activity.
Subsequently, highly dispersed palladium was deposited on the supported HT catalyst, and the catalytic properties were investigated in the single-stage synthesis of MIBK from acetone and $\mathrm{H}_{2}$. Because characterization by spectroscopic techniques is restricted by the nature of the support, we used electron microscopy, $\mathrm{N}_{2}$ physisorption, $\mathrm{CO}_{2}$ and $\mathrm{H}_{2}$ chemisorption, $\mathrm{X}$-ray diffraction, and TGA-MS to characterize the HTs supported on CNF skeins.

\section{Experimental}

\subsection{Carbon nanofiber growth}

For the growth of CNF, $18 \mathrm{wt} \% \mathrm{Ni} / \mathrm{SiO}_{2}$ was prepared by incipient wetness impregnation using $1.7-\mathrm{mm}$ silica spheres (Engelhard; $\mathrm{SA}=60 \mathrm{~m}^{2} \mathrm{~g}^{-1}, \mathrm{PV}=1.0 \mathrm{ml} \mathrm{g}^{-1}$ ) and nickel nitrate (Acros). The impregnated support was dried in static air at room temperature before calcination at $873 \mathrm{~K}\left(5 \mathrm{~K} \mathrm{~min}^{-1}\right)$ for $3 \mathrm{~h}$. The Ni catalyst precursor $(1.5 \mathrm{~g})$ was reduced in situ at $973 \mathrm{~K}$ in a fixed-bed reactor for $2 \mathrm{~h}$ in a $20 \% \mathrm{H}_{2} / \mathrm{N}_{2}$ flow $\left(400 \mathrm{ml} \mathrm{min}^{-1}\right)$. Next, the temperature was decreased to $843 \mathrm{~K}$, and methane $\left(25 \% \mathrm{CH}_{4}\right)$ balanced with $\mathrm{N}_{2}$ was passed through the reactor for $19 \mathrm{~h}$ at a pressure of $1 \mathrm{bar}$ and a total flow of $400 \mathrm{ml} \mathrm{min}^{-1}$. The sample thus obtained is denoted as CNF.

To remove the silica support, CNF samples were refluxed for $2 \mathrm{~h}$ in a $1 \mathrm{M} \mathrm{KOH}$ solution, washed, and then refluxed in concentrated nitric acid for $2 \mathrm{~h}$ to remove exposed $\mathrm{Ni}$ and to introduce oxygen-containing groups. Next, the samples were filtered, thoroughly washed with demineralized water, and dried at $393 \mathrm{~K}$ for $24 \mathrm{~h}$ (further denoted as $\mathrm{CNF}_{\mathrm{ox}}$ ).

\subsection{Assembly and activation of $M g / A l$ HTs supported by $C N F$}

Supported Mg/Al HTs $(\mathrm{Mg} / \mathrm{Al}=2)$ were prepared by pore precipitation, which involved subsequent incipient wetness impregnation of the constituents. First, $3.2 \mathrm{~g} \mathrm{CNF}_{\mathrm{ox}}$ was impregnated with $2.1 \mathrm{ml}$ of an aqueous solution containing both $(1.4 \mathrm{M}) \mathrm{Mg}\left(\mathrm{NO}_{3}\right)_{2} \cdot 6 \mathrm{H}_{2} \mathrm{O}$ (Acros) and $(0.71 \mathrm{M}) \mathrm{Al}\left(\mathrm{NO}_{3}\right)_{3}$. $9 \mathrm{H}_{2} \mathrm{O}$ (Merck). The impregnated support was dried in static air at room temperature for $1 \mathrm{~h}$, followed by drying at $393 \mathrm{~K}$ for $1 \mathrm{~h}$. Next, the material was impregnated with $1.9 \mathrm{ml}$ of an aqueous solution containing both $(8.3 \mathrm{M}) \mathrm{NaOH}$ (Merck) and $(0.56 \mathrm{M}) \mathrm{Na}_{2} \mathrm{CO}_{3}$ (Acros). The impregnated support was placed in a Teflon holder and placed in an autoclave. The samples were heated to the desired temperature ( 333 or $423 \mathrm{~K}$ ), kept at that temperature for $20 \mathrm{~h}$ in a water-saturated atmosphere, and then dried at $333 \mathrm{~K}$ in static air. The catalyst precursor was thoroughly washed with demineralized water and dried at $393 \mathrm{~K}$ for $20 \mathrm{~h}$. The samples are further denoted by, for example, $\mathrm{HT} / \mathrm{CNF}_{\mathrm{as}, 333}$. All other supported HT samples were denoted by the stage of activation and the synthesis temperature, for example, $\mathrm{HT} / \mathrm{CNF}_{\text {act, } 423}$.

$\mathrm{HT} / \mathrm{CNF}_{\text {as }}$ samples were activated $[4,13]$ by heating in a nitrogen flow to $773 \mathrm{~K}\left(10 \mathrm{~K} \mathrm{~min}^{-1}\right)$ for $8 \mathrm{~h}$, followed by rehydration at room temperature using a decarbonated water-saturated nitrogen flow of $150 \mathrm{ml} \mathrm{min}^{-1}$ for $48 \mathrm{~h}$, and were stored under nitrogen atmosphere. 
Unsupported HT with a $\mathrm{Mg} / \mathrm{Al}$ ratio of 2 was prepared via co-precipitation [38]. To an aqueous solution $(75 \mathrm{ml})$ containing $0.35 \mathrm{~mol} \mathrm{NaOH}$ (Merck) and $0.09 \mathrm{~mol} \mathrm{Na}_{2} \mathrm{CO}_{3}$ (Acros), an aqueous solution $(50 \mathrm{ml})$ of $0.1 \mathrm{~mol} \mathrm{Mg}\left(\mathrm{NO}_{3}\right)_{2} \cdot 6 \mathrm{H}_{2} \mathrm{O}$ (Acros) and $0.05 \mathrm{~mol} \mathrm{Al}\left(\mathrm{NO}_{3}\right)_{3} \cdot 9 \mathrm{H}_{2} \mathrm{O}$ (Merck) was added. The resulting white suspension was heated to $333 \mathrm{~K}$ for $24 \mathrm{~h}$ under vigorous stirring, after which the precipitate was filtered off and washed extensively. The sample, further denoted as $\mathrm{HT}_{\mathrm{as}}$, was dried for $24 \mathrm{~h}$ at $393 \mathrm{~K} . \mathrm{HT}_{\mathrm{as}}$ was activated via heat treatment at $723 \mathrm{~K}$ and rehydration (further denoted as $\mathrm{HT}_{\mathrm{act}}$ ).

\subsection{Deposition of Pd on $H T / C N F$}

Palladium (2 wt \%) was deposited on $\mathrm{HT} / \mathrm{CNF}_{\mathrm{as}, 333}$ via wet impregnation with $\mathrm{Pd}(\mathrm{acac})_{2}$. Typically, $\mathrm{HT} / \mathrm{CNF}_{\mathrm{as}, 333}$ was added to a solution of $\mathrm{Pd}(\mathrm{acac})_{2}$ in toluene. The solvent was evaporated under continuous stirring of the suspension and applying a dynamic vacuum. The catalyst precursor was heated in an Ar flow at $773 \mathrm{~K}\left(5 \mathrm{~K} \mathrm{~min}^{-1}\right)$ for $2 \mathrm{~h}$, after which the temperature was lowered to the reduction temperature $(523 \mathrm{~K})$ and maintained there for $2 \mathrm{~h}$ in $\mathrm{H}_{2}$ flow. The sample was rehydrated as described above and further denoted as PdHT/CNF $\mathrm{Cat}_{\text {act }}$.

\subsection{Catalyst characterization}

Powder X-ray diffraction (XRD) patterns were measured using an Enraf-Nonius CPS 120 powder diffraction apparatus with $\mathrm{Co}-\mathrm{K}_{\alpha}$ radiation $(\lambda=1.789 \AA) . \mathrm{N}_{2}$ physisorption measurements were performed using a Micromeritics Tristar 3000 analyzer after drying the samples at $393 \mathrm{~K}$ for at least $20 \mathrm{~h}$. Volumetric $\mathrm{CO}_{2}$ adsorption measurements in the range of $0-50$ mbar were executed at $273 \mathrm{~K}$ with a Micromeritics ASAP $2010 \mathrm{C}$ apparatus after drying the samples at $393 \mathrm{~K}$ in vacuum for at least $20 \mathrm{~h}$. The total number of accessible sites was determined taking the amount of $\mathrm{CO}_{2}$ chemisorbed to zero pressure by extrapolation of the linear part of the uptake isotherm. Hydrogen chemisorption data on PdHT/CNF samples were recorded using a Micromeritics ASAP 2010C apparatus. Before the chemisorption measurements at $343 \mathrm{~K}$, samples were dried in vacuo at $393 \mathrm{~K}$ for $16 \mathrm{~h}$, reduced in $\mathrm{H}_{2}$ flow at $423 \mathrm{~K}$ for $2 \mathrm{~h}\left(5 \mathrm{~K} \mathrm{~min}^{-1}\right)$, and degassed for two $\mathrm{h}$ at the reduction temperature. The $\mathrm{H} / \mathrm{M}$ ratios are based on the amount of hydrogen adsorbed by extrapolating the linear part of the isotherm of the total amount of adsorbed hydrogen to zero pressure. TGA-MS analyses were carried out with a Netzsch STA-429 thermobalance. Samples were heated up to $1230 \mathrm{~K}$ in an Ar flow at a rate of $5 \mathrm{~K} \mathrm{~min}^{-1}$. The gases evolved during analysis were monitored using a Fisons Thermolab quadropole mass spectrometer. Burn-off experiments were performed by heating the samples up to $1230 \mathrm{~K}$ in a flow of $20 \% \mathrm{O}_{2} / \mathrm{Ar}$ at a rate of $5 \mathrm{~K} \mathrm{~min}^{-1}$. The amount of HTs present was calculated from TGA results, after correction for $\mathrm{CNF}_{\mathrm{ox}}$, by assuming that the weight loss due to the decomposition of the HT was $45 \%$. The tensile failure of the spheres was determined with the side crushing strength (SCS) test. Statistical information was obtained by determining the average SCS value of multiple particles by applying increasing contact forces on a particle between two flat plates. The SCS value is the force $(\mathrm{N})$ needed to break the particle. A Philips XL30FEG electron microscope equipped with an EDX detector for elemental analysis was used to obtain SEM images. TEM images were obtained with a Philips CM-200 FEG TEM operating at $200 \mathrm{kV}$ equipped with an EDX detector. Various sample preparations were used to investigate whether HT was strongly adhered to CNF. After ultrasonic treatment of 30 or $60 \mathrm{~s}$ in ethanol, samples were dispersed on a holey carbon film supported on a copper grid. A third sample was prepared by dipping the grid in the ground sample. Statistical information on HT platelet size (lateral dimension) was obtained by determining the platelet size of $50 \mathrm{HT}$ platelets during TEM analysis. The pore volume of $\mathrm{CNF}_{\mathrm{ox}}$ was determined by incipient wetness impregnation of demineralized water at room temperature.

\subsection{Catalytic experiments}

The self-condensation of acetone was performed under $\mathrm{N}_{2}$ atmosphere in a stirred double-walled thermostatically cooled glass reactor, equipped with baffles. Typically, $1.8 \mathrm{~mol}$ of acetone (Merck) was cooled to $273 \mathrm{~K}$, and $1.0 \mathrm{~g}$ of crushed (20$100 \mu \mathrm{m}$ particles) HT/CNF catalyst or $0.30 \mathrm{~g} \mathrm{HT}_{\text {act }}$ was added. The single-stage synthesis of MIBK at $331 \mathrm{~K}$ was performed in a semibatch slurry reactor operating at a constant $\mathrm{H}_{2}$ pressure of 1.2 bar [23,39] with similar amounts as in the condensation of acetone. Aliquots of $1 \mathrm{ml}$ were taken from the reaction mixture during reaction and analyzed using a Chrompack CP 9001 GC provided with a Chrompack CP 9050 autosampler. Iso-octane (Acros) was used as an internal standard. Blank experiments showed that neither the $\mathrm{CNF}_{\text {ox }}$ support nor $\mathrm{HT} / \mathrm{CNF}_{\text {as }}$ exhibited catalytic activity in the condensation of acetone.

\section{Results and discussion}

\subsection{Growth of CNF bodies}

Fig. 1 shows the growth catalyst and the resulting spherical carbon bodies grown out of methane at $843 \mathrm{~K}$. The CNF bodies are enlarged replicas of the growth catalyst. As was found

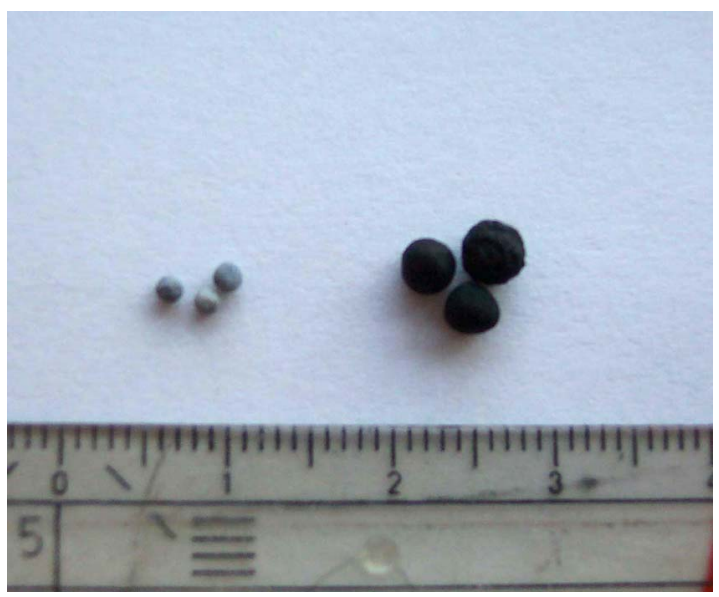

Fig. 1. The $\mathrm{Ni} / \mathrm{SiO}_{2}$ spherical particles and the resulting carbon bodies grown out of methane at $843 \mathrm{~K}$. Length scale is in centimeters. 

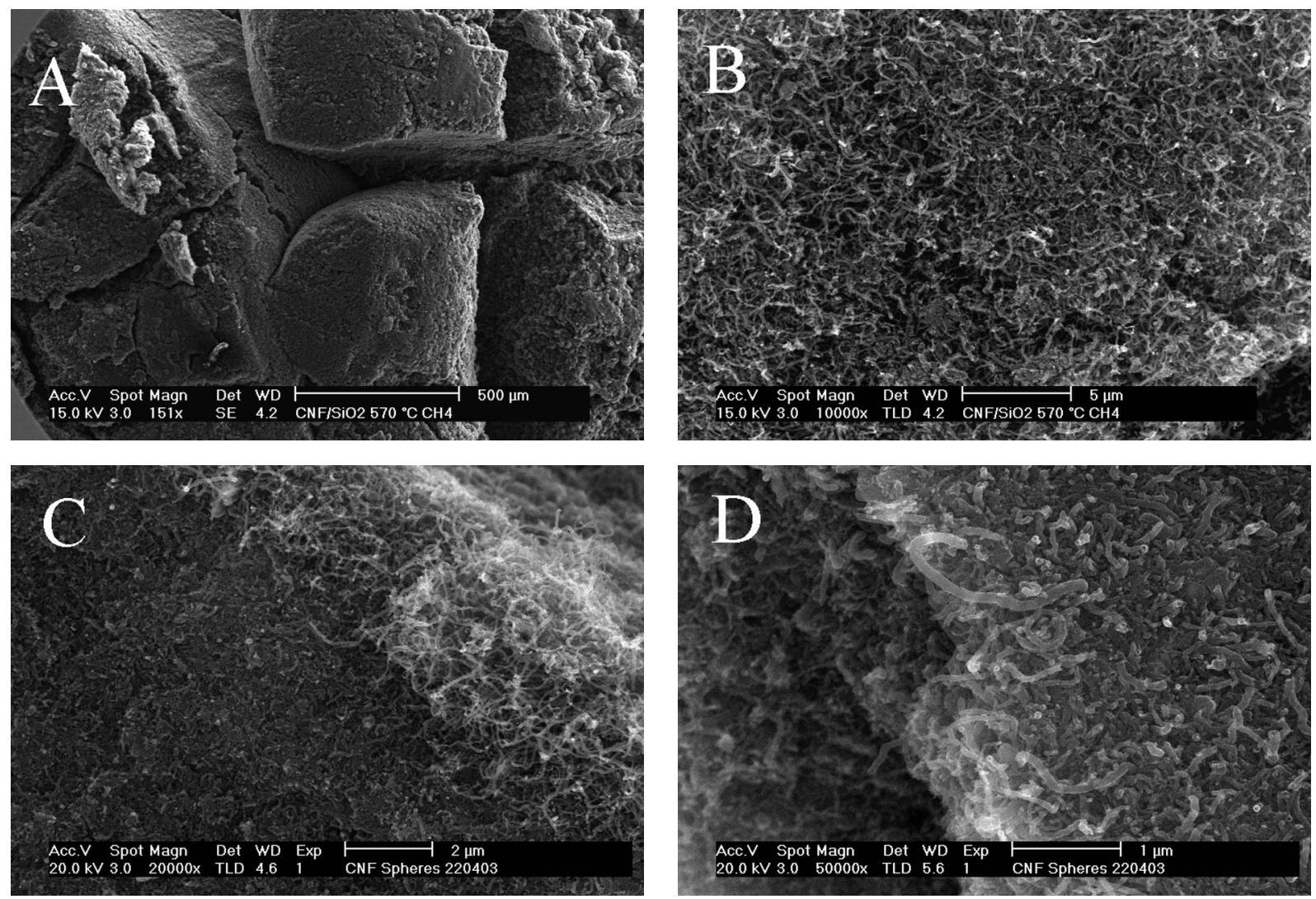

Fig. 2. SEM micrographs of CNF after treatment in $\mathrm{KOH}$ at various magnifications. (A) Outer surface of spherical carbon body (low magnification). (B) Outer surface of the sphere (high magnification). (C) Internal (left) and external surface (top right) of the sphere obtained upon cutting. (D) Inside of the sphere.

by Teunissen et al. [34], the shape of the resulting CNF bodies is highly dependent on the shape of the growth catalyst. The increase in diameter was about 2-fold, and the increase in weight was by a factor of $6-7$.

To obtain more detailed information about the structure of the CNF spheres, SEM analysis at various magnifications was performed (Fig. 2). Low-magnification SEM can distinguish cracks of 100-200 $\mu \mathrm{m}$ in the CNF spheres; higher magnification shows the interwoven fibers. At the edges of the cracks and the outer surface of the spheres, the CNF skeins are rather open. However, on cutting the spherical particles, the fibers appear to be densely packed on the inside of the particle with a less dense outer layer of $2 \mu \mathrm{m}$ (Figs. $2 \mathrm{C}$ and 2D).

To remove the growth catalyst, the CNF spheres were subjected to a treatment in $\mathrm{KOH}$ solution and subsequently in concentrated $\mathrm{HNO}_{3}$. The pore volume of the thus pretreated carbon bodies as determined by impregnation of water is appreciable, that is, $0.60-0.65 \mathrm{~cm}^{3} \mathrm{~g}^{-1}$. Table 1 presents some physicochemical properties of the carbon materials. It is worth mentioning that growth from methane resulted in strong CNF spheres, whereas growth from synthesis gas $\left(\mathrm{CO} / \mathrm{H}_{2}\right)$ resulted in soft lumps. To obtain more quantitative information about the strength of the carbon bodies, SCS tests were performed. After removal of the growth catalyst, we observed a high SCS value for $\mathrm{CNF}_{\text {ox }}$, that is, $41 \mathrm{~N}$. A SCS value of $13 \mathrm{~N}$ was determined for the original $\mathrm{Ni} / \mathrm{SiO}_{2}$ growth catalyst.
Table 1

Physico-chemical properties of the various $\mathrm{HT} / \mathrm{CNF}$ materials and $\mathrm{HT}_{\mathrm{act}}$

\begin{tabular}{|c|c|c|c|c|c|}
\hline & $\begin{array}{l}S_{\mathrm{BET}} \\
\left(\mathrm{m}^{2} \mathrm{~g}^{-1}\right)\end{array}$ & $\begin{array}{l}S_{\mathrm{BET}} \\
\left(\mathrm{m}^{2} \mathrm{~g}_{\mathrm{CNF}}^{-1}\right)\end{array}$ & $\begin{array}{l}V_{\text {meso }} \\
\left(\mathrm{cm}^{3} \mathrm{~g}^{-1}\right)\end{array}$ & $\begin{array}{l}\text { HT loading }{ }^{\mathrm{a}} \\
\text { (wt\%) }\end{array}$ & $\begin{array}{l}\text { SCS value } \\
\text { (N) }\end{array}$ \\
\hline CNF & 69 & $71^{\mathrm{b}}$ & 0.36 & - & 35 \\
\hline $\mathrm{CNF}_{\mathrm{OX}}$ & 89 & 89 & 0.47 & - & 41 \\
\hline $\mathrm{HT} / \mathrm{CNF}_{\mathrm{as}, 333}$ & 72 & 81 & 0.35 & 11.3 & n.d. \\
\hline $\mathrm{HT} / \mathrm{CNF}_{\mathrm{act}, 333}$ & 77 & 87 & 0.37 & 11.3 & 38 \\
\hline $\mathrm{HT} / \mathrm{CNF}_{\text {used }, 333^{\mathrm{c}}}$ & 80 & 90 & 0.33 & 11.0 & n.d. \\
\hline $\mathrm{HT}_{\text {act }}$ & 69 & - & 0.38 & 100 & n.d. \\
\hline
\end{tabular}

\footnotetext{
a Determined by TGA-MS

b $S_{\mathrm{BET}}$ of CNF after correction for the presence of the $\mathrm{Ni} / \mathrm{SiO}_{2}$ growth catalyst.

c After two catalytic runs.
}

\subsection{Assembly and activation of HTs on CNF}

Fig. 3A shows the TGA-MS results of $\mathrm{CNF}_{\mathrm{ox}}$. On heat treatment in Ar up to $1230 \mathrm{~K}$, considerable weight loss was found, accompanied by evolution of $\mathrm{H}_{2} \mathrm{O}, \mathrm{CO}_{2}$, and $\mathrm{CO}$. Besides the weight loss due to the evolution of physisorbed water around $393 \mathrm{~K}$, these distinctive weight losses are due to the presence of carboxylic acid groups $\left(\mathrm{CO}_{2}\right)$ and phenol-type groups $(\mathrm{CO})$ introduced by the treatment in concentrated nitric acid [35,40-44]. Fig. 3B displays a typical TGA-MS profile of $\mathrm{HT} / \mathrm{CNF}_{\mathrm{as}}$. In general, our TGA-MS results obtained with unsupported HT with interlayer $\mathrm{CO}_{3}{ }^{2-}$ reveal two distinct weight losses with the evolution of water and $\mathrm{CO}_{2}$ with 

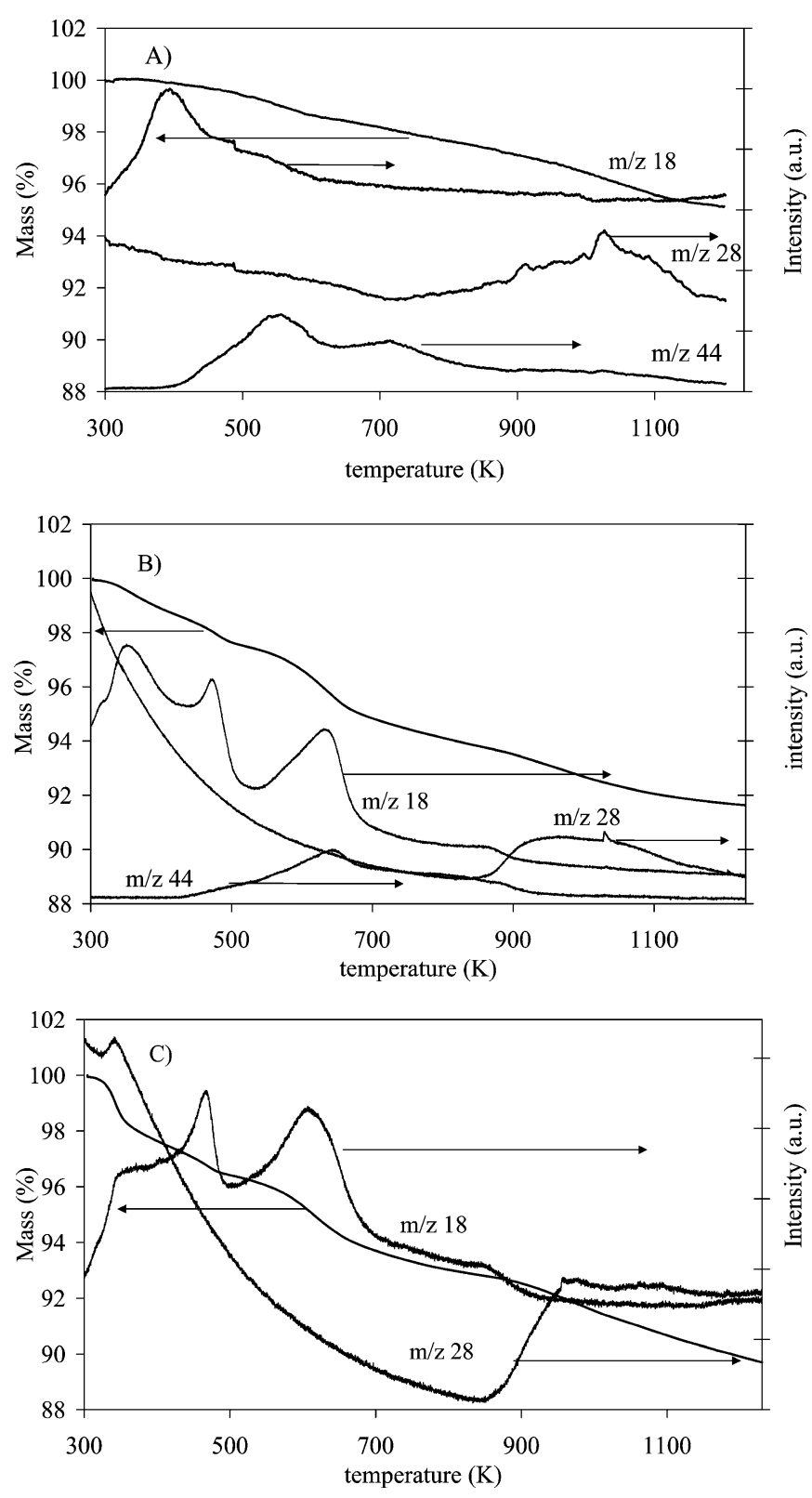

Fig. 3. TGA-MS of (A) $\mathrm{CNF}_{\mathrm{OX}}$. (B) $\mathrm{HT} / \mathrm{CNF}_{\mathrm{as}, 333}$. (C) $\mathrm{HT} / \mathrm{CNF}_{\mathrm{act}, 333}$ heated in Ar flow.

a total weight loss of $45 \%$. First, the removal of interlayer water can be observed at temperatures up to $473-483 \mathrm{~K}$; second, dehydroxylation and decarboxylation is observed above $573 \mathrm{~K}$ $[1,45]$. This pattern of decomposition is rather specific for HT. Comparing the TGA-MS profiles of $\mathrm{CNF}_{\mathrm{ox}}$ and the HT/CNF samples, we can conclude that HT is indeed present in the CNF bodies.

From the TGA-MS results measured in Ar as well as in $\mathrm{O}_{2}$ (i.e., the total burn-off experiments), we calculated an HT content of $11 \mathrm{wt} \%$ in these $\mathrm{HT} / \mathrm{CNF}_{\mathrm{as}, 333}$ bodies (Table 1). When applying more concentrated impregnate solutions, loadings of around $16 \mathrm{wt} \%$ of HT were obtained. Li et al. [46] prepared $\mathrm{Ni}-\mathrm{Al}$ HTs on carbon nanotubes by coprecipitation from diluted solution of the Ni-Al HTs. We investigated what weight percentage HT could be applied with this procedure $[23,38]$ in

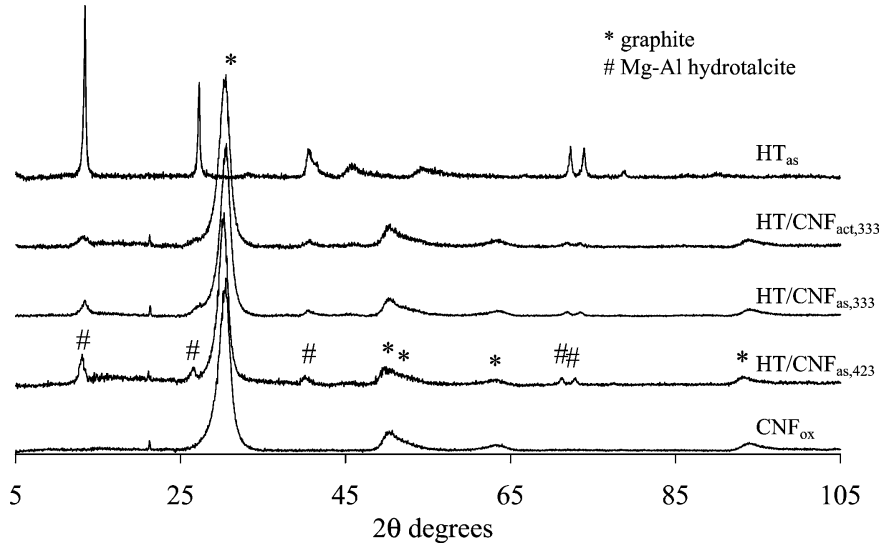

Fig. 4. XRD diffraction patterns of $\mathrm{CNF}_{\mathrm{ox}}, \mathrm{HT}_{\mathrm{as}}$ and $\mathrm{HT} / \mathrm{CNF}$ samples.

the presence of CNF spheres. In this experiment, the volume of the reaction mixture exceeded the pore volume of the CNF bodies by a factor of 14 . We found that only $3.3 \mathrm{wt} \%$ of HT was applied in the CNF bodies via this method, considerably lower than the amount of HT applied with the consecutive impregnation method that we describe.

After activation of $\mathrm{HT} / \mathrm{CNF}_{\mathrm{as}, 333}$ via heat treatment and subsequent rehydration, TGA-MS results demonstrated the presence of an HT phase in the CNF spheres (Fig. 3C). The weight percentage of activated HT in CNF was about equal to that of $\mathrm{HT} / \mathrm{CNF}_{\mathrm{as}, 333}$, that is, $11 \mathrm{wt} \%$.

Fig. 4 shows the XRD patterns of the materials at different stages of the synthesis procedure. For reference, this figure also includes the patterns of $\mathrm{CNF}_{\mathrm{ox}}$ and $\mathrm{HT}_{\mathrm{as}}$. In the $\mathrm{HT} / \mathrm{CNF}_{\mathrm{as}}$ and $\mathrm{HT} / \mathrm{CNF}_{\text {act }}$ patterns, diffraction lines due to the presence of HT can be distinguished next to the strong lines of the CNF support. The most intense line of HT in the HT/CNF patterns is seen at $13.2^{\circ} 2 \theta$ (003 line), representing the lattice distance of one cation layer and one interlayer distance (7.7 $\AA$ ). Moreover, the other peaks in the patterns of HT/CNF correspond well with the typical features of $\mathrm{HT}_{\mathrm{as}}$. Furthermore, the diffraction lines in the $\mathrm{HT} / \mathrm{CNF}_{\mathrm{as}, 33}$ and $\mathrm{HT} / \mathrm{CNF}_{\mathrm{as}, 423}$ patterns are broader than those observed in $\mathrm{HT}_{\mathrm{as}}$, implying that the HT crystallites in $\mathrm{HT} / \mathrm{CNF}_{\mathrm{as}}$ are smaller than those of $\mathrm{HT}_{\mathrm{as}}$. Comparing the pattern of $\mathrm{HT} / \mathrm{CNF}_{\mathrm{as}, 423}$ with that of $\mathrm{HT} / \mathrm{CNF}_{\mathrm{as}, 333}$, the peak broadening in $\mathrm{HT} / \mathrm{CNF}_{\mathrm{as}, 423}$ is less pronounced, as would be expected when increasing the crystallization temperature $[13,19]$. After heating the catalyst precursors up to $773 \mathrm{~K}$ in nitrogen flow, the layered structure is destroyed and a mixed oxide is formed. Rehydration of the samples results in the reconstruction of the layered structure to a large extent $[4,12-14,23]$. The presence of HT in the CNF spheres after activation $\left(\mathrm{HT} / \mathrm{CNF}_{\mathrm{act}, 333}\right)$ is evident from the diffraction pattern, although even further line broadening is apparent, and the relative intensity of the characteristic peaks of HT to the most intense graphite reflection is decreased.

From the nitrogen adsorption and desorption isotherms of $\mathrm{CNF}_{\mathrm{ox}}$ and $\mathrm{HT} / \mathrm{CNF}_{\mathrm{as}, 333}$, shown in Fig. 5, we can deduce the presence of cylindrical mesopores with open ends at both sides. Both samples have a broad pore size distribution; see Fig. 6 . 


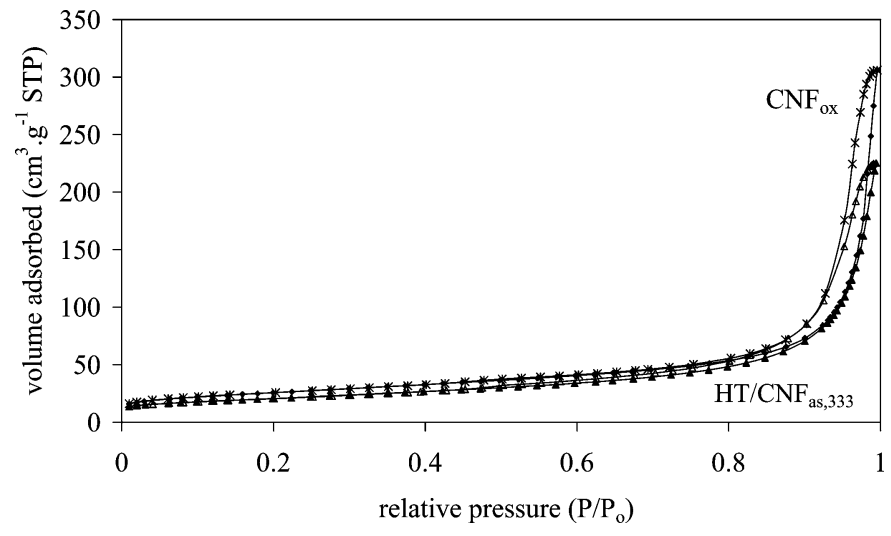

Fig. 5. Nitrogen adsorption and desorption isotherms of $\mathrm{CNF}_{\mathrm{Ox}}$ and $\mathrm{HT} / \mathrm{CNF}_{\mathrm{as}, 333}$.

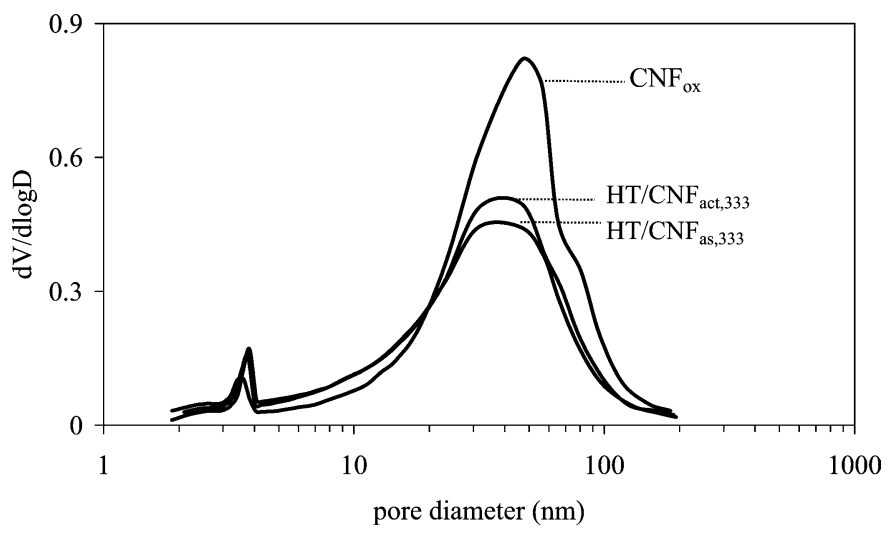

Fig. 6. Pore size distributions of $\mathrm{CNF}_{\mathrm{ox}}, \mathrm{HT} / \mathrm{CNF}_{\mathrm{as}, 333}$ and $\mathrm{HT} / \mathrm{CNF}_{\mathrm{act}, 333}$ calculated from the desorption branch using the $\mathrm{BJH}$ method.

The sharp peak at 3-4 $\mathrm{nm}$ is an artifact of the Barret-JoynerHalenda (BJH) model due to closing of the hysteresis loop. A somewhat smaller mean pore diameter was found with the HT/CNF samples due to coverage of the carbon nanofibers. We attribute the main part of the pore volume to the open space between the cylindrical fibers, although a minor part could be due to the presence of inner tubes [36,37].

Table 1 shows the results derived from nitrogen physisorption of the various $\mathrm{HT} / \mathrm{CNF}$ materials and $\mathrm{HT}_{\mathrm{act}}$. $\mathrm{HT} / \mathrm{CNF}_{\mathrm{as}, 333}$ exhibited a BET surface area and pore volume significantly lower than that measured with $\mathrm{CNF}_{\mathrm{ox}}$, indicating that the pores of the carbon bodies are partly filled by HT. The absence of micropores and the high average pore diameter (Fig. 6) suggest that although some filling of the pores occurs, the material has a readily accessible pore system. The decreased BET surface area after inclusion of HT is largely accounted for by the loading of CNF by HT, because the surface area per gram of CNF remains almost constant (Table 1). As a result of the heat treatment of $\mathrm{HT} / \mathrm{CNF}_{\mathrm{as}, 333}$ at $773 \mathrm{~K}$ and subsequent rehydration, surface area and pore volume increased slightly, as was observed by Roelofs et al. with unsupported HTs [13]. The strength of the spherical catalyst particles was maintained, and an average SCS value of $38 \mathrm{~N}$ was found.

EDX line scans obtained with SEM revealed $\mathrm{Mg}$ and $\mathrm{Al}$ $(\mathrm{Mg} / \mathrm{Al}$ ratio of 2) through the macroscopic bodies of the cat-

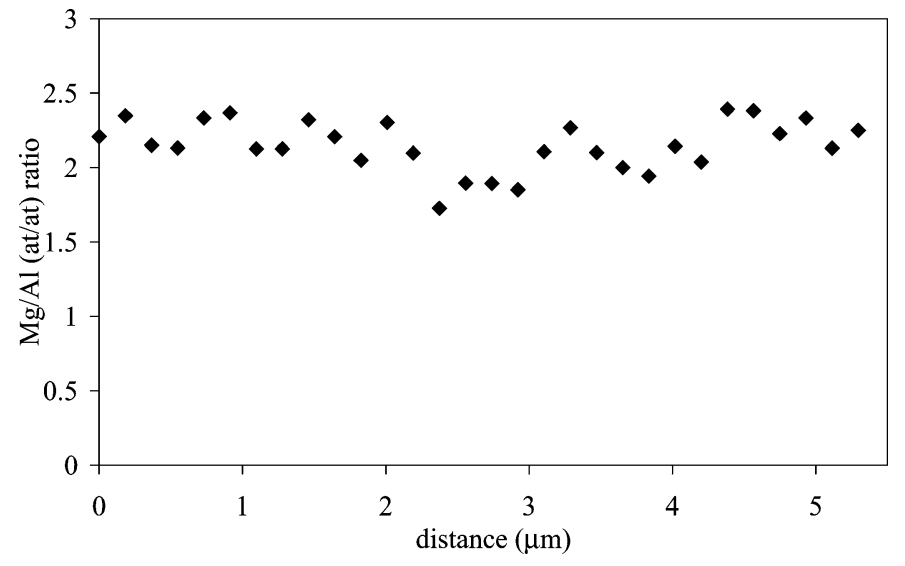

Fig. 7. The atomic $\mathrm{Mg} / \mathrm{Al}$ ratio of $\mathrm{HT} / \mathrm{CNF}_{\mathrm{as}, 333}$ as monitored with SEM-EDX line scan through part of a catalyst particle.

alyst (example given in Fig. 7). TEM analysis revealed small hexagonal HT crystallites present on the carbon nanofibers, visible as small platelets (Fig. 8A-C). The HT platelet size distribution in the lateral dimension of $\mathrm{HT} / \mathrm{CNF}_{\mathrm{as}, 333}$ is given in Fig. 9. The average platelet size of $21 \mathrm{~nm}$ corresponds well with the size calculated from the line broadening in the XRD pattern of the (110) diffraction line using the Scherrer equation (i.e., $20 \mathrm{~nm}$ ). The lateral platelet size of $\mathrm{HT} / \mathrm{CNF}_{\mathrm{as}, 333}$ was much smaller than that of $\mathrm{HT}_{\text {as }}$ (i.e., $\sim 60 \mathrm{~nm}$ ); see Fig. 10. EDX analyses during TEM performed on the HT/CNF samples detected $\mathrm{Mg}$ and $\mathrm{Al}$ on the platelet-like structures (example given in Fig. 8D; EDX, spot size 3-4 nm, indicated with a thick arrow in Fig. 8C), but not on seemingly bare fibers. TEM did not show HT platelets separate from the fibers on the sample grid. Furthermore, by varying the sample preparation method for TEM analysis, we investigated to what extent the HT crystallites exhibited strong interaction with CNF. Two samples were prepared by an ultrasonic treatment after suspending crushed $\mathrm{HT} / \mathrm{CNF}_{\mathrm{as}, 333}$ in ethanol. A third sample was prepared by only dipping the sample holder in the crushed catalyst. Even after an ultrasonic treatment in ethanol of $60 \mathrm{~s}$, TEM analysis showed similar results as obtained with the sample prepared without this ultrasonic treatment. These results indicate that the HT phase was strongly adhered to the carbon nanofibers, not just entrapped in the porous structure.

\subsection{Deposition of Pd on $H T / C N F$}

Two methods of $\mathrm{Pd}$ deposition on $\mathrm{HT} / \mathrm{CNF}_{\mathrm{as}, 333}$ were investigated: ion adsorption using $\mathrm{Pd}\left(\mathrm{NH}_{3}\right)_{4}\left(\mathrm{NO}_{3}\right)_{2}$, as described elsewhere [23], and a wet-impregnation method using $\operatorname{Pd}(\mathrm{acac})_{2}$. The best results were obtained with the wet impregnation method ( $\left.\mathrm{PdHT} / \mathrm{CNF}_{\mathrm{act}}\right)$. TEM examination of this latter catalyst showed that palladium was deposited on $\mathrm{HT} / \mathrm{CNF}_{\mathrm{as}, 33}$ as small particles $(\sim 2-5 \mathrm{~nm}$; see Fig. 11); this was confirmed by $\mathrm{H}_{2}$ chemisorption results. The concordant results of TEM and $\mathrm{H}_{2}$ chemisorption clearly indicate that $\mathrm{Pd}$ is not covered up by HT and is well accessible for catalysis. Pd is largely present on CNF in view of the limited coverage of CNF with HT. 

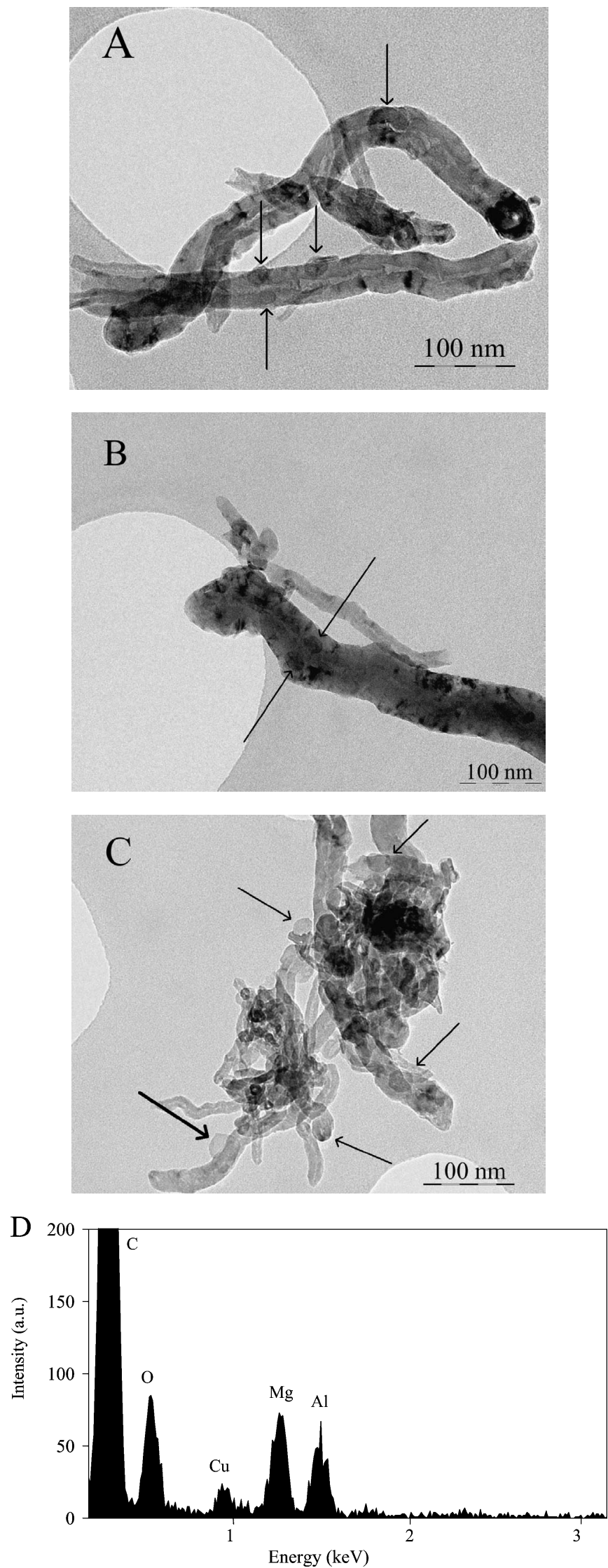

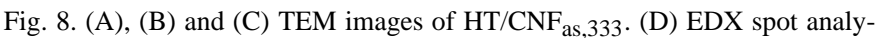
sis of area indicated with a thick arrow in (C). Some other HT platelets are indicated by thin arrows.

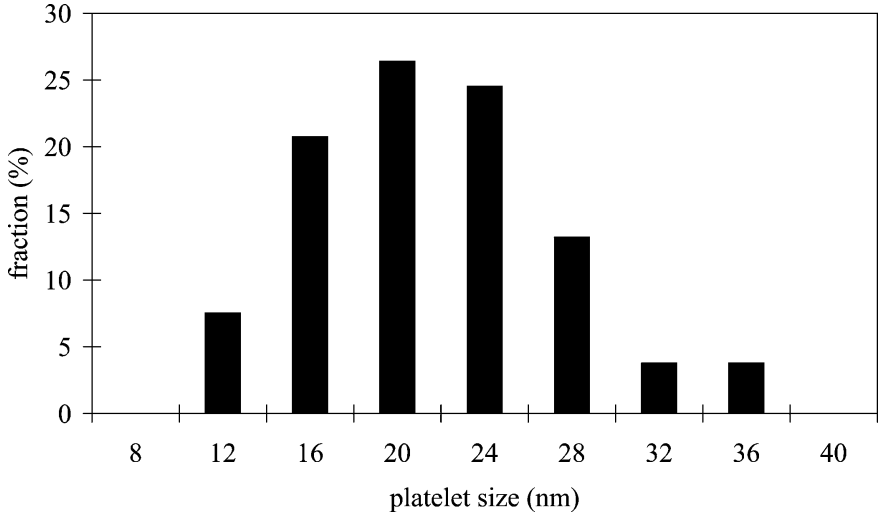

Fig. 9. Hydrotalcite platelet size distribution (lateral dimension) of $\mathrm{HT} / \mathrm{CNF}_{\mathrm{as}, 333}$.

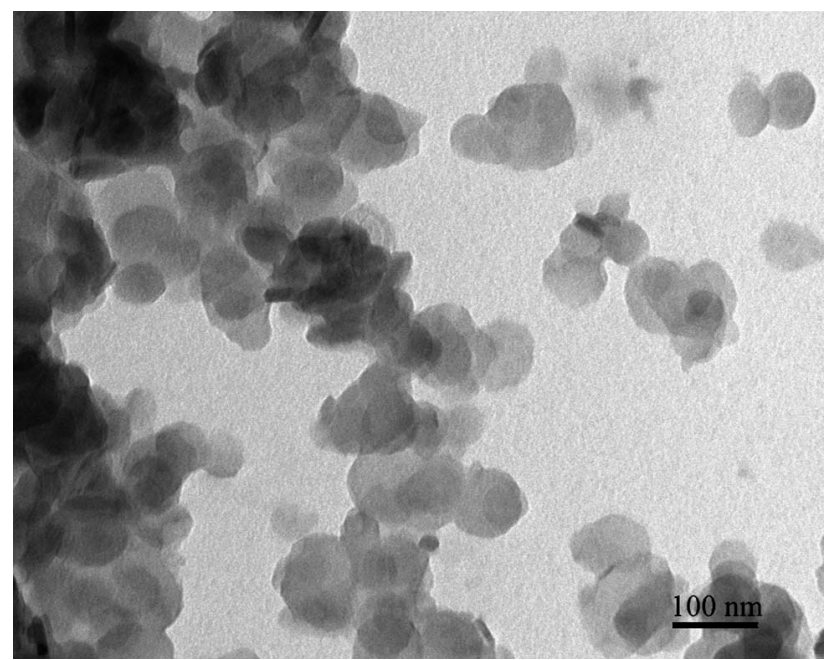

Fig. 10. TEM image of $\mathrm{HT}_{\mathrm{as}}$, synthesized at $333 \mathrm{~K}$.

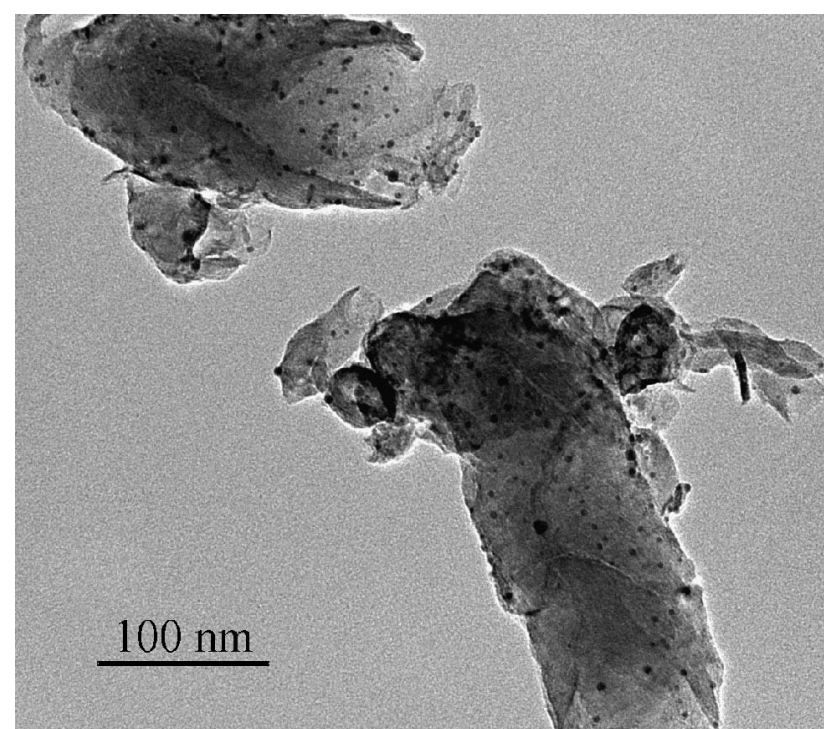

Fig. 11. TEM micrograph of PdHT/CNF act. 
Table 2

Initial reaction rates and turn over frequencies (TOF) for acetone self-condensation at $273 \mathrm{~K}$ with the HT catalysts

\begin{tabular}{|c|c|c|c|c|}
\hline & $\begin{array}{l}\mathrm{CO}_{2} \text { adsorption } \\
\left(\mathrm{mmol} \mathrm{g}_{\mathrm{HT}}^{-1}\right)\end{array}$ & $\begin{array}{l}\text { Initial rate }^{\mathrm{a}} \\
\left(\mathrm{mmol}_{\text {DAA }} \mathrm{g}_{\text {cat }}^{-1} \mathrm{~h}^{-1}\right)\end{array}$ & $\begin{array}{l}\text { Initial rate }{ }^{\mathrm{a}} \text { (HT-based) } \\
\left(\text { mmol }_{\text {DAA }} \mathrm{g}_{\mathrm{HT}}^{-1} \mathrm{~h}^{-1}\right)\end{array}$ & $\begin{array}{l}\mathrm{TOF}^{\mathrm{a}} \\
\left(\mathrm{s}^{-1}\right)\end{array}$ \\
\hline $\mathrm{HT}_{\text {act }}$ & 0.16 & 134 & 134 & 0.46 \\
\hline $\mathrm{HT} / \mathrm{CNF}_{\mathrm{as}, 333}$ & n.d. & 0 & 0 & - \\
\hline $\mathrm{HT} / \mathrm{CNF}_{\mathrm{act}, 333}$ & 0.75 & 61 & 542 & 0.40 \\
\hline $\mathrm{HT} / \mathrm{CNF}_{\text {react, } 333^{\mathrm{b}}}$ & n.d. & 56 & 513 & - \\
\hline $\mathrm{HT} / \mathrm{CNF}_{\text {act }, 423}$ & 0.34 & 23 & 210 & 0.35 \\
\hline
\end{tabular}

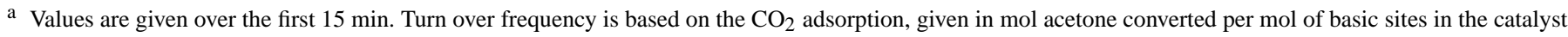
per second.

b After reactivation via heat treatment and rehydration of $\mathrm{HT} / \mathrm{CNF}_{\mathrm{used}}$.

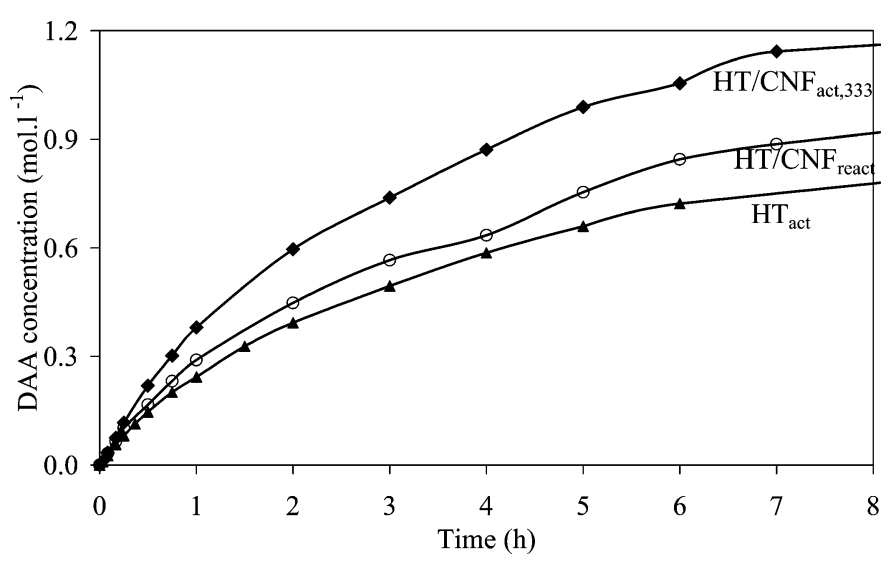

Fig. 12. DAA production at $273 \mathrm{~K}$ in 1.8 mole acetone with $0.3 \mathrm{~g} \mathrm{HT}$ act $(\boldsymbol{\Delta})$,

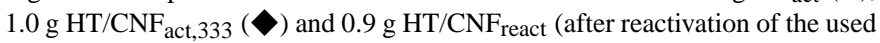
catalyst) $(\mathrm{O})$.

\subsection{Catalytic properties and characterization of the used catalyst}

\subsubsection{Condensation of acetone at $273 \mathrm{~K}$}

We investigated the performance of the HT/CNF samples in the liquid-phase self-condensation of acetone and found that $\mathrm{HT} / \mathrm{CNF}_{\mathrm{as}}$ samples did not display any condensation activity due to the absence of Brønsted base sites [4,14,15,23]. Fig. 12 and Table 2 show the results using $\mathrm{HT}_{\text {act }}$ and $\mathrm{HT} / \mathrm{CNF}_{\mathrm{act}, 333}$. High activity for diacetone alcohol (DAA) formation over $\mathrm{HT} / \mathrm{CNF}_{\mathrm{act}, 333}$ was observed (Table 2) after $23 \mathrm{~h}$ in a DAA concentration of $1.37 \mathrm{moll}^{-1}$, which is close to the equilibrium value of $1.57 \mathrm{moll}^{-1}$ [47]. The selectivity to DAA was $>98 \%$, with the side products mesityl oxide (MO) and triacetone alcohol. $\mathrm{HT}_{\mathrm{act}}$ exhibited high initial activity in the condensation as well, with rates comparable with those reported previously $[13,14]$. It is important to emphasize that the $\mathrm{HT} / \mathrm{CNF}_{\text {act, } 333}$ activity based on the weight of $\mathrm{HT}$ present in the sample is extremely high (Table 2); that is, the specific activity of $\mathrm{HT} / \mathrm{CNF}_{\mathrm{act}, 333}$ is about four times that of $\mathrm{HT}_{\text {act }}$. Because $\mathrm{CO}_{2}$ has been successfully applied as probe molecule to gain information about the number of basic sites in activated HTs [4, $12,13,48]$, the total number of accessible active sites in the supported and unsupported catalysts was determined with volumetric $\mathrm{CO}_{2}$ measurements at low pressures (Table 2). A relatively

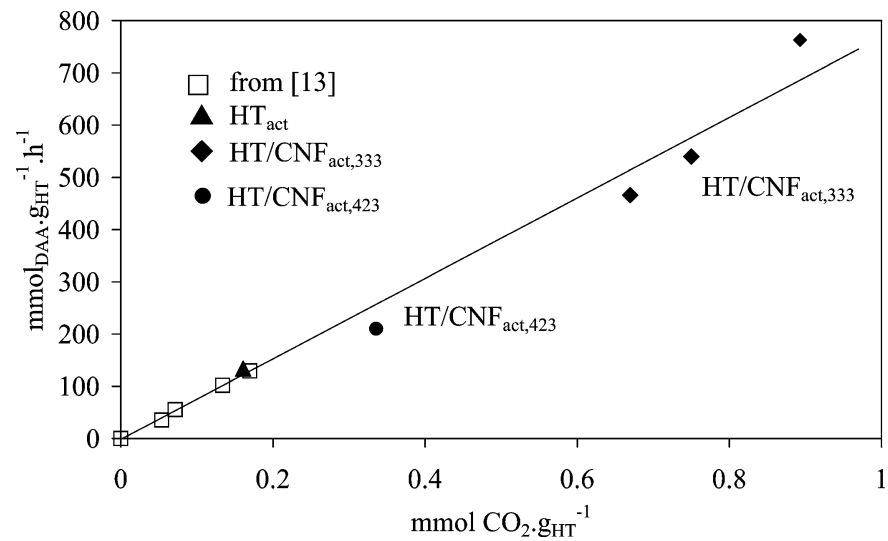

Fig. 13. Initial activity in the condensation of acetone at $273 \mathrm{~K}$ vs. $\mathrm{CO}_{2}$ adsorption over unsupported activated HTs $(\square, \boldsymbol{\Delta})$ and $\mathrm{HT}_{\mathrm{CNF}} \mathrm{act}(\boldsymbol{\bullet}, \boldsymbol{\bullet})$ samples.

high number of active sites of $\mathrm{HT} / \mathrm{CNF}_{\mathrm{act}}$ samples compared with $\mathrm{HT}_{\text {act }}$ was found, which is due to the much smaller crystallites as found with XRD and TEM. The number of active sites is determined by the lateral size of the platelets, because these are most likely situated at the edges of the platelets. The turnover frequencies (TOFs) in the condensation of acetone at $273 \mathrm{~K}$ are about the same for the supported and unsupported materials.

Fig. 13 shows the initial activities of $\mathrm{HT}_{\mathrm{act}}, \mathrm{HT} / \mathrm{CNF}_{\mathrm{act}, 423}$, and several $\mathrm{HT} / \mathrm{CNF}_{\mathrm{act}, 333}$ samples versus the number of accessible sites as measured by $\mathrm{CO}_{2}$ adsorption. For reference, the correlation with activated HTs with different platelet sizes found by Roelofs et al. [13] is also given. As can be concluded based on Fig. 13, the correlation of activated HTs is valid over a wide range, because the extrapolation of this correlation to the $\mathrm{HT} / \mathrm{CNF}_{\mathrm{act}}$ samples is very good. Our study further indicates that the active sites participating in catalysis are most likely situated at the edges of the platelets [13, $14,25]$, in contrast to recent reports by other researchers on the structure and activity of activated HTs as solid base catalysts that proposed a correlation between activity and surface area $[24,49]$. Note the significant improvement in efficiency of the supported HT samples compared with the unsupported HT samples and to recently reported values with activated HTs in aldol-type condensation reactions [13,14,24, $25]$. 
Abelló et al. [24,25] recently reported on the correlation between the surface area of the activated HTs and the activity found in the condensation of citral with acetone at $333 \mathrm{~K}$. However, because the surface area of the material is not dependent on the lateral size of the platelets but mainly on the degree of stacking (i.e., the thickness of the platelets), a correlation between surface area and catalytic performance is not expected. We investigated, using the results from $\mathrm{N}_{2}$ physisorption, whether such a correlation can be derived for the condensation of acetone at $273 \mathrm{~K}$ using the catalysts reported here, those reported by Abelló et al. [25], and those reported by Roelofs et al. [12,13]. However, no obvious correlation could be derived. Calculation of the specific surface area (HT-based) of our supported catalyst using the thickness $(6 \mathrm{~nm})$ and the lateral size $(20 \mathrm{~nm})$ as determined by TEM and XRD gives around $260 \mathrm{~m}^{2} \mathrm{~g}_{\mathrm{HT}}^{-1}$ [note that the value derived from $\mathrm{N}_{2}$ physisorption $\left(66 \mathrm{~m}^{2} \mathrm{~g}_{\mathrm{HT}}^{-1}\right)$ is much lower due to the effect of the carbon nanofibers], which is similar to the surface area reported by Abelló et al. [25] (i.e., $270 \mathrm{~m}^{2} \mathrm{~g}^{-1}$ ). However, the specific activity of our supported catalysts in the condensation of acetone at $273 \mathrm{~K}$ is $>10$ times that reported by those authors. As can be concluded from Fig. 13, the supposition that the platelet size in the lateral dimension determines the number of active sites, and thereby the performance of the catalyst, is much more likely.

A directly reused $\mathrm{HT} / \mathrm{CNF}_{\mathrm{act}, 333}$ sample, after filtration under nitrogen, showed significantly lower activity than the initial run, that is, 8.4 mmol $_{\text {DAA }} \mathrm{g}_{\text {cat }}^{-1} \mathrm{~h}^{-1}$. This could be due to adsorption of side products or loss of HT from the CNF bodies during the first run. Reactivation of the used catalyst was applied by a repeated heat treatment and rehydration procedure. The initial activity of the original catalyst for the condensation of acetone at $273 \mathrm{~K}$ was almost restored (Table 2; Fig. 12). With TGA-MS, we established the amount of HT remaining in the used catalyst after two catalytic runs. Results obtained in Ar flow demonstrated that the characteristic weight losses of HT due to the evolution of water and $\mathrm{CO}_{2}$ were still present in the TGA-MS profile. Furthermore, the amount of HT calculated from TGA-MS in Ar and the burn-off experiments (Table 1) again was $11 \mathrm{wt} \%$, demonstrating that no loss of HT material from the CNF bodies had occurred. To further support the absence of HT leaching, in another experiment we filtered off the $\mathrm{HT} / \mathrm{CNF}_{\mathrm{act}, 333}$ catalyst after $5 \mathrm{~min}$ of reaction. The filtrate was kept at room temperature in $\mathrm{N}_{2}$ atmosphere for $7 \mathrm{~h}$, after which the total amount of DAA formed was determined. No extra DAA was formed after the catalyst was removed.

\subsubsection{Single-stage synthesis of MIBK at $331 \mathrm{~K}$}

In a recent study, we showed that with a physical mixture of Pd supported on CNF and unsupported activated HTs, acetone and $\mathrm{H}_{2}$ are converted to MIBK under mild conditions with appreciable rate and high selectivity, with the dehydration of DAA to MO as the rate-limiting step [23]. Once we significantly improved the activity of the HT catalyst, we investigated $\mathrm{PdHT} / \mathrm{CNF}_{\text {act }}$ in the single-stage synthesis of MIBK, wherein all catalytic functions are present in the same catalyst. Fig. 14 displays the formation of DAA, MO, and MIBK. The condensation of acetone to DAA was very rapid compared with the rate of dehydration of DAA to MO, which remained low due to the rapid hydrogenation of MO to MIBK. Selectivity to the desired products (DAA, MO, and MIBK) was $>99 \%$.

The initial activity of $\mathrm{PdHT} / \mathrm{CNF}_{\text {act }}$ in the condensation of acetone appeared to be 5 times higher than that measured with the physical mixture (Table 3), similar to the results obtained in the condensation of acetone at $273 \mathrm{~K}$. The activity in the dehydration reaction over $\mathrm{PdHT} / \mathrm{CNF}_{\text {act }}$ was also considerably higher, hereby improving the production rate of MIBK (albeit by less than a factor of 2). Table 3 also gives the TOF values for the condensation and dehydration based on the $\mathrm{CO}_{2}$ measurements. The TOF in the condensation reaction was similar between both catalysts; however, the TOF in the dehydration reaction differed significantly. Although this difference could be ascribed to deactivation of the catalyst due to the relatively low amount of HT present in the PdHT/CNF act catalyst, further research is needed to elucidate the structure-activity relationship in this reaction.

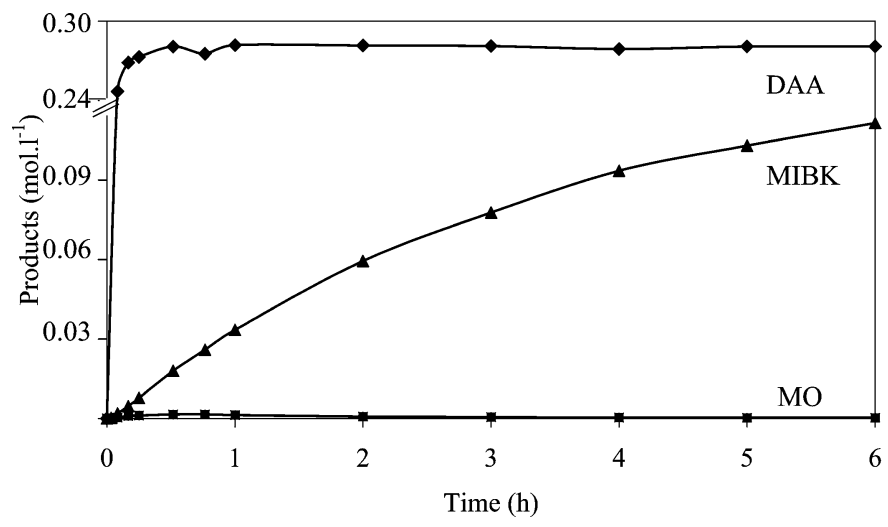

Fig. 14. Formation of DAA, MO and MIBK in the single-stage synthesis of MIBK at $331 \mathrm{~K}$ and 1.2 bar $\mathrm{H}_{2}$ over $1 \mathrm{~g}$ of PdHT/ $\mathrm{CNF}_{\text {act }}$ in $1.8 \mathrm{~mol}$ acetone.

Table 3

Single-stage production of MIBK at $331 \mathrm{~K}$ and 1.2 bar $\mathrm{H}_{2}$ over PdHT/CNF act and over a physical mixture of activated hydrotalcites and Pd on CNF

\begin{tabular}{|c|c|c|c|c|c|c|}
\hline & \multicolumn{3}{|c|}{ Activity $\left(\operatorname{mol}_{\text {product }} \mathrm{g}_{\mathrm{HT}}^{-1} \mathrm{~h}^{-1}\right)^{\mathrm{a}}$} & \multirow{2}{*}{$\begin{array}{l}\text { Selectivity } \\
(\%)^{\mathrm{b}}\end{array}$} & \multicolumn{2}{|l|}{$\operatorname{TOF}\left(\mathrm{s}^{-1}\right)^{\mathrm{a}}$} \\
\hline & $\mathrm{DAA}^{*}$ & MO & MIBK & & Condensation* & Dehydration \\
\hline $\mathrm{HT}_{\text {act }}$ and $\mathrm{Pd} / \mathrm{CNF}^{\mathrm{c}}$ & 1.3 & 0.026 & 0.023 & 95 & 4 & 0.08 \\
\hline $\mathrm{PdHT} / \mathrm{CNF}_{\text {act }}$ & 7.1 & 0.043 & 0.040 & 99 & 5 & 0.03 \\
\hline
\end{tabular}

a Activity and TOF calculated over the first $30 \mathrm{~min}$ or when marked with * over the first $5 \mathrm{~min}$. The activity and TOF in the dehydration reaction was calculated from the sum of MO and MIBK formed.

b Selectivity to DAA, MO and MIBK after $6 \mathrm{~h}$ (at $\sim 3 \%$ acetone conversion)

c Taken from [23], physical mixture of $0.3 \mathrm{~g} \mathrm{HT}_{\text {act }}$ and $0.2 \mathrm{~g}$ Pd supported on CNF in $1.8 \mathrm{~mol}$ acetone were initially present. 


\section{Conclusions}

We have demonstrated that activated HTs supported on $\mathrm{CNF}$ bodies exhibit much greater catalytic activity in the selfcondensation of acetone than unsupported activated HTs. This high reactivity must be ascribed to the HT crystallites with extremely small sizes in the lateral dimension $(\sim 20 \mathrm{~nm})$, which implies a high number of active edge sites. The correlation between the number of accessible active sites and the initial activity in the self-condensation of acetone is extended over a wide range. Our results show that loss of HT from the CNF bodies during catalysis is absent, while the activity can be restored via a repeated thermal activation procedure. By depositing Pd on the supported HT catalyst an efficient bi-functional catalyst for the single-stage synthesis of MIBK from acetone and $\mathrm{H}_{2}$ could be obtained. The highly active and selective carbon nanofibers-supported HTs catalyst can be interesting in various applications, slurry phase as well as in fixed bed reactors, due to the favorable physico-chemical properties, the macroscopic size and the mechanical strength of the catalyst bodies.

\section{Acknowledgments}

The authors thank C. van der Spek, A. Broersma, A.J.M. Mens, M. Versluijs-Helder, M.K. van der Lee, and J.D. Meeldijk for their technical assistance. Financial support was provided by the Netherlands Technology Foundation (grant CW/ STW 790.35.733).

\section{References}

[1] F. Cavani, F. Trifiro, A. Vaccari, Catal. Today 11 (1991) 173.

[2] M.K. Kantam, B.M. Choudary, C.V. Reddy, K.K. Rao, F. Figueras, Chem. Commun. 9 (1998) 1033.

[3] B. Choudary, M.L. Kantam, C.R.V. Reddy, K.K. Rao, F. Figueras, J. Mol. Catal. A 146 (1999) 279.

[4] K.K. Rao, M. Gravelle, J. Sanchez-Valente, F. Figueras, J. Catal. 173 (1998) 115.

[5] M.J. Climent, A. Corma, S. Iborra, A. Velty, J. Catal. 221 (2004) 474.

[6] D. Tichit, B. Coq, S. Cerneaux, R. Durand, Catal. Today 75 (2002) 197.

[7] Á. Mastalir, J. Ocskó, React. Kinet. Catal. Lett. 74 (2001) 323.

[8] S. Narayanan, K. Krishna, Appl. Catal. A 174 (1998) 221.

[9] Y.Z. Chen, B.J. Liaw, H.R. Tan, K.L. Shen, Appl. Catal. A 169 (1998) 207.

[10] D. Tichit, M.H. Lhouty, A. Guida, B. Chiche, F. Figueras, A. Auroux, D. Bartalini, E. Garrone, J. Catal. 151 (1995) 50.

[11] D. Tichit, M.N. Benanni, F. Figueras, R. Tessier, J. Kervennal, Appl. Clay Sci. 13 (1998) 401.

[12] J.C.A.A. Roelofs, A.J. van Dillen, K.P. de Jong, Catal. Lett. 74 (2001) 91.

[13] J.C.A.A. Roelofs, D.J. Lensveld, A.J. van Dillen, K.P. de Jong, J. Catal. 203 (2001) 184.
[14] J.C.A.A. Roelofs, A.J. van Dillen, K.P. de Jong, Catal. Today 60 (2000) 297.

[15] A. Guida, L.M. Hassane, D. Tichit, F. Figueras, P. Geneste, Appl. Catal A 164 (1997) 251.

[16] C. Noda Perez, C.A. Perez, C.A. Henriques, J.L.F. Monteiro, Appl. Catal. A 272 (2004) 229.

[17] W. Kagunya, P. Dutta, Z. Lei, Physica B 234-236 (1997) 910.

[18] S.P. Newman, W. Jones, New J. Chem. (1998) 105.

[19] W.T. Reichle, Solid State Ionics 22 (1986) 135.

[20] W.T. Reichle, J. Catal. 63 (1980) 295.

[21] N. Das, D. Tichit, R. Durand, P. Graffin, B. Coq, Catal. Lett. 71 (2001) 181.

[22] F. Prinetto, D. Tichit, R. Tessier, B. Coq, Catal. Today 55 (2000) 103.

[23] F. Winter, A.J. van Dillen, K.P. de Jong, J. Mol. Catal. A 219 (2004) 273.

[24] S. Abelló, F. Medina, D. Tichit, J. Pérez-Ramírez, Y. Cesteros, P. Salagre, J.E. Sueiras, Chem. Commun. 11 (2005) 1453.

[25] S. Abelló, F. Medina, D. Tichit, J. Pérez-Ramírez, J.C. Groen, J.E. Sueiras, P. Salagre, Y. Cesteros, Chem. Eur. J. 11 (2005) 728

[26] D. Tichit, B. Coq, Cattech 7 (2004) 206.

[27] F. Winter, A.J. van Dillen, K.P. de Jong, Chem. Commun. 31 (2005) 3977.

[28] A.A. Nikolopoulos, G.B. Howe, B.W.-L. Jang, R. Subramanian, J.J. Spivey, D.J. Olsen, T.J. Devon, R.D. Culp, Catal. Org. React. 82 (2001) 533.

[29] R. Unnikrishan, S. Narayanan, J. Mol. Catal. A 144 (1999) 173.

[30] M. Ogawa, H. Kaiho, Langmuir 18 (2002) 4240.

[31] K.P. de Jong, J.W. Geus, Catal. Rev. Sci. Eng. 42 (2000) 481.

[32] P. Serp, M. Corrias, P. Kalck, Appl. Catal. A 253 (2003) 337.

[33] V.B. Fenelonov, A.Y. Derevyankin, L.G. Okkel, L.B. Avdeeva, V.I. Zaikovskii, E.M. Moroz, A.N. Salanov, N.A. Rudina, V.A. Likholobov, S.K. Shakhutdinov, Carbon 35 (1997) 1129.

[34] W. Teunissen, PhD thesis, Utrecht University, The Netherlands, 2000.

[35] T.G. Ros, A.J. van Dillen, J.W. Geus, D.C. Koningsberger, Chem. Eur. J. 8 (2002) 1151

[36] M.L. Toebes, J.M.P. van Heeswijk, J.H. Bitter, A.J. van Dillen, K.P. de Jong, Carbon 42 (2004) 307.

[37] F. Winter, G.L. Bezemer, C. van der Spek, J.D. Meeldijk, A.J. van Dillen, J.W. Geus, K.P. de Jong, Carbon 43 (2005) 327.

[38] S. Miyata, T. Kumura, Chem. Lett. (1973) 843

[39] T.G. Ros, D.E. Keller, A.J. van Dillen, J.W. Geus, D.C. Koningsberger, J. Catal. 211 (2002) 85.

[40] M.L. Toebes, F.F. Prinsloo, J.H. Bitter, A.J. van Dillen, K.P. de Jong, J. Catal. 214 (2003) 78

[41] S.S. Barton, M.J.B. Evans, E. Halliop, J.A.F. MacDonald, Carbon 35 (1997) 1361.

[42] H.P. Boehm, Carbon 32 (1994) 759.

[43] C. Moreno-Castilla, M.A. Ferro-Garcia, J.P. Joly, I. Bautista-Toledo, F. Carrasco-Marin, J. Rivera-Utrilla, Langmuir 11 (1995) 4386.

[44] J.L. Figueiredo, M.F.R. Pereira, M.M.A. Freitas, J.J.M. Órfão, Carbon 37 (1999) 1379.

[45] J.C.A.A. Roelofs, J.A. van Bokhoven, A.J. van Dillen, J.W. Geus, K.P. de Jong, Chem. Eur. J. 8 (2002) 5571.

[46] C. Li, K. Yao, J. Liang, Appl. Catal. A 261 (2004) 221.

[47] G.G. Podrebarac, F.T.T. Ng, G.L. Rempel, Chem. Eng. Sci. 52 (1997) 2991.

[48] J. Sanchez Valente, F. Figueras, M. Gravelle, P. Kumbhar, J. Lopez, J.-P. Besse, J. Catal. 189 (2000) 370.

[49] M.J. Climent, A. Corma, S. Iborra, K. Epping, A. Velty, J. Catal. 225 (2004) 316 . 